\title{
What is technology?
}

Some of the most famous ANT cases have investigated the role of a range of technologies, including aeroplanes, ships, microscopes and a personal rapid-transport system. Technologies are frequently forefronted in ANT work in a reflection of the equal emphasis ANT places on humans and non-humans, with technologies often taking the form of significant non-human actants. In this book I am similarly interested in the non-human actants in sport and take these as my starting-point when investigating technologies. I am particularly interested in the way that the physical properties of the technology, and its precise material forms, can facilitate or produce particular effects and actions. At the same time, in line with the ANT approach, it is impossible to confine any discussion of technology to purely material forms. Instead, I consider the network that produced and utilises the technology to be of equal interest.

This chapter investigates three ways that technology can be understood through ANT, all of which are drawn upon at various times in the book. First, technology is considered as a multiple, heterogeneous assemblage; second, it is seen as a stabilising device; and third, it appears as an actant. This chapter considers how these three views of technology are highly relevant to understanding the role of technologies within sporting practice.

\section{Technology as a heterogeneous assemblage}

One of the most famous philosophers to write about technology, Martin Heidegger (1977, p. 1), argued that it is both a 'means to an end' and a 'human activity. These combined definitions suggest that technology is something that humans utilise in order to achieve particular goals. Heidegger (1977) emphasised that human use of technology entailed mastery and that mastery was particularly important in order to avoid humans losing control of it. 
Heidegger's position has been adopted by several authors writing on sport and technology. For example, Van Hilvoorde, Vos and de Wert (2007, p. 175) echoed this position when describing technology in sport, arguing that technology is part of the artificiality that defines sport, including 'mastery of technological equipment or the body [in order] to achieve the particular goals of a specific contest'. Similarly, Loland $(2002$, p. 3) claimed that the view of technology as 'human-made means to reach human interests and goals' is the definition used most frequently within writings on technology in sport. Both these definitions acknowledge that in sport there are particular goals that must be met, and that technologies act as artificially created ways by which these goals can be realised.

Latour (1999b) derives his own definition of technology through framing it in opposition to Heidegger. Latour disagrees with Heidegger's definition of technology as incorporating mastery, even though he notes that technology is both something that can master nature and humans and something that can be mastered by humans. Latour rejects Heidegger's view of technology, instead arguing that, when humans and technology assemble together, a third actor is created that has different properties from the separate components. He emphasises that it is the combined potential of disparate parts that produces a working piece of technology. Riis (2008) argues that Latour's and Heidegger's views are not that different, with Latour misinterpreting Heidegger. She argues that Heidegger, far from arguing for the existence of total mastery by either humans or technology, acknowledges that the acts of humans are influenced by technology and vice versa. Her interpretation suggests that both Heidegger and Latour emphasise the heterogeneous nature of technology and see technology as working with multiple actors in order to be effective.

In taking this argument further, Latour and Venn (2002, p. 248) use the term 'fold' to describe how they see the various heterogeneous actors that make up technology combining within it. Using the example of the hammer, they describe how the hammer exists as an accumulation of various histories, including the 'antiquity of the planet' through the mineral form of the aged oak in the handle, along with 'the forests of the Ardennes, the mines of the Ruhr, the German factory, the tool van which offers discounts every Wednesday on Bourbonnais streets, and finally the workshop of a particularly clumsy Sunday bricoleur' (Latour and Venn, 2002, p. 249). The example of the hammer demonstrates the notion of technology as an assemblage, or actor-network, of heterogeneous histories, both human and non-human. The ANT approach emphasises the relationships between things, acknowledging that technologies can work to connect actants together (Harvey and Knox, 2014, p. 6). For example, the 
quotation above describes a range of different actants that are brought together through the hammer, with the hammer existing as a network encompassing all these disparate components that make it into a distinct object.

In order to emphasise the view of technologies as networks, Latour (1999b, p. 191) posits that this position is easier to understand through the use of the word 'technical' rather than either of 'technology' or 'technique'. He gives four reasons for this argument. First, he suggests that 'technical' implies that numerous programmes are in action. For example, when we say 'this is a technical point', the phrase is used to denote a deviation from, or a section of, a larger project. Therefore the word 'technical' acknowledges the existence of multiple programmes, or sections of the network. Second, Latour notes how 'technical' highlights the existence of non-humans as actors, in influencing and affecting the social world and therefore connected to and part of it. Third, he argues that 'technical' can also refer to a hitch in the programme, implying that technology can act to inhibit action, but that the technology is also part of the programme. This definition mirrors the concept of the mediator, which will be discussed below. Finally, 'technical skill' can refer to a specialised skill which produces action when combined with particular technologies in a network arrangement, therefore again encompassing the notion of technology existing as a network.

In defining technologies as networks, further discussion of the term 'network' is necessary. Latour (1999a) argues that the term 'Actor-Network Theory' is a misnomer, since these three words, and the hyphen, suggest an alternative meaning to what Latour and other ANT theorists originally envisaged. In terms of the word 'network', Latour (1999a) describes how this word came into use in ANT studies prior to the invention of the internet, yet with the ubiquity of the internet the word has come to be understood as the creation of instantaneous ties and connections. Latour (1999a) argues that this is the exact opposite of the original intention. He argues that the use of the word was intended to refer to a concept similar to Deleuze's 'rhizome', which refers to 'a series of transformations' (Latour, 1999a, p. 15), meaning that the connections between the disparate parts connect the network together and transform its use and its meaning.

There are strong connections between the work of Deleuze and Guattari and some of the central concepts in ANT. As per above, Latour prefers the concept of the rhizome to the word 'network', as this concept acknowledges that every point can potentially connect with any other point and that these connections can result in transformations. Throughout this book, several examples 
demonstrate how the rhizome, or network, operates. In several cases, sporting bodies of all kinds introduce new technologies with a particular goal in mind, but in all cases, unexpected consequences are generated owing to the technology connecting, interacting and transforming an unanticipated part of the sporting network.

Like Latour, Deleuze and Guattari opposed the notion of singularity, instead emphasising that all things exist as multiple through their use of the term 'assemblage' (Deleuze and Guattari, 2004), a word also used at times by Latour. Like Latour, they argued against stability, claiming that assemblages are not made up of discrete, bounded bodies, but rather that things are made of disparate parts while also making up parts of other things (Currier, 2003; Deleuze and Guattari, 2004). This is akin to Latour's example of the hammer, which, as described earlier, has a number of historical and geographical components folded within it in order for it to be stabilised and be recognised as a hammer. At the same time, the hammer is also part of a variety of other networks, which include human builders, businesses selling tools and other larger manufacturing organisations.

In sport, any piece of technology can be similarly examined. For example, at the material level, a basketball is made up of the disparate components of rubber or leather, air and an inner bladder. When combined with the flesh of a human, who is also composed of particular chemicals, hormones, bones and muscles as well as training and knowledge, the basketball is transformed into something that can bounce on the ground or pass through the air. The need for a ball made of rubber that can bounce with ease while a player is walking or running came about owing to the particular circumstances of the invention of the game of basketball. The inventor of the game, James Naismith, was limited to using a flat indoor space to create a game to be played during the cold Massachusetts winter. He used the indoor gymnasium, peach baskets and a soccer ball (Rust, 2003), which were all easily available. Naismith found that versions of soccer or rugby were impossible in the indoor environment because kicking the ball smashed windows while tackling caused bruises on the athletes' bodies because of the hard wooden floor. He recalled a game from his childhood called 'Duck on a Rock', which involved 'lobbing small stones up at a softball-sized rock on a boulder about 20 feet away' (Cantwell, 2004, p. 1076) and altered it to become a game playable in the flat indoor gymnasium. The peach baskets were nailed to the walls at each end and a soccer ball used for play, as these were the only items to be found that would work for his idea. To get the ball out of the peach baskets, someone had to climb a stepladder or use a pole. Naismith quickly wrote a set of thirteen rules, which involved 
no carrying of the ball, integrating bouncing instead, and these rules formed the basis of what became known as basketball (Cantwell, 2004; Rust, 2003).

This popular story of the creation of basketball is an excellent example of how sport works as a heterogeneous network where humans and non-human technologies are equally important. While it is agreed the idea for basketball and the rules were Naismith's (Cantwell, 2004; Rust, 2003), the game was created through the assembling of humans and non-humans. First, one non-human actant, the weather, created the circumstance where a new indoor game was required. If Naismith had been living in the tropics, this would not have been necessary. Second, the availability of the peach baskets, the round soccer ball and the indoor gymnasium with a flat floor were all crucial in being able to play the game. But at the same time the network included human input. Naismith's own knowledge of a game he enjoyed as a child was an important part of the creation of the game. Following the network further, the sports commonly played in North America at the time - football, track and baseball - left a gap in the calendar which had to be filled. Therefore the network included aspects that may be considered by some theorists as micro actors, such as the individual school situation, together with what may be termed macro actors, such as the yearly sports calendar. All these heterogeneous components are folded within the network of the technology that we refer to as basketball.

Currently, to consider the modern basketball network, the humble game of basketball is now the centre of a large, commercialised league that consists of a huge number of courts, hoops, players, teams and sponsors, all of whom are also assemblages of various disparate components and combine together in a multitude of ways. The word 'basketball' refers to every aspect of this network, including human components such as players, coaches and managers, and non-human components such as balls, wooden floors, shoes, backboards and hoops.

While the above demonstrates how non-humans play a role in sport, their importance can be understood further through paying attention to the way the human body works with non-humans in order to create sport. As the philosopher of sport Loland (2002) describes, technologies are not merely instruments utilised in sport; they are also constituent in producing sport. Or, as Thorpe and Rinehart (2010, p. 1273) argue, objects such as surfboards and skateboards, as used in alternative sports, 'are not merely objects that participants throw, kick, swing or push; these are objects that define the very activity itself'. They describe how alternative sports participants do not see themselves as separate from the objects they use but, in participating in the 
activity, become one with it. For example, using the examples of surfing and skateboarding, Thorpe and Rinehart (2010, p. 1273) write:

Acknowledging the significant role of equipment in surfing, Ford and Brown refer to the board as a 'hybrid extension of the body', while Borden describes the skateboard as 'a prosthetic device, an extension of the body as a kind of fifth limb, absorbed into and diffused inside the body-terrain encounter'.

In describing the surfboard in this way, the surfer resembles a form of cyborg, with the material form of the surfboard feeling to the surfer like part of their body. Introna (2009, p. 26) notes how the use of a theory acknowledging the interconnection between humans and technologies is particularly relevant as the world moves to becoming more technologically mediated and 'cyborgian'. In sociology of sport, a growing number of authors are examining the way athletes negotiate the connections between the natural and the artificial (see, for example, Butryn, 2003; Butryn and Masucci, 2003; Butryn and Masucci, 2009; Chapman, 1997; Cole, 1993, 1998; Miah, 2004; Shogan, 1999; Wesley, 2001). As Butryn and Masucci (2009, p. 287) note, there is a debate over whether twenty-first-century sport is transgressing the natural/artificial boundary, and there is a wish revealed by some sporting participants to keep sport 'pure' or solely human, and untarnished by the introduction of artificial technologies.

One of the unique and somewhat controversial points of ANT is the argument that boundaries such as the natural/artificial divide have never existed. In one of his most famous works, We Have Never Been Modern, Latour (1993a) confronts this divide. He notes that, while many theorists argue that modernity marks a shift towards a focus on humanity which was seen as separate from the natural, this view is a particular interpretation that does not stand up to detailed analysis. As Venn and Featherstone (2006) explain, if one were to start making a list of all the features of a modern society and then try to identify whether individual societies match the list, it would quickly become evident that very few societies, if any, would definitely do so. Instead, they argue that most societies have a range of features that may be argued to be modern and some that are not. They use the example of the USA, which may be argued to be a quintessential modern society, with its emphasis on capitalist progress, and argue that it does not fit the categorisation of a modern society entirely, owing to the dominance of religious views within it, which is argued to be the hallmark of a traditional society. Societies are instead a mix of ideas that may be termed either modern or traditional depending on interpretation, with no definitive boundary existing between the two. 
Sport is no exception. As Jonasson (2014) argues, sport has both modern and traditional components. On the one hand, as Guttmann (1978) argues, sport includes a list of features that would generally be considered to indicate modernity, including rationalisation, secularisation, specialisation and others. From this viewpoint, technologies are acknowledged as a necessary component in the enactment of sport (Jonasson, 2014). On the other hand, some sporting regulations seem interested in retaining a level of purity that harks back to the traditional amateur understanding of sport. This is particularly the case with doping regulations, which (as discussed in more detail in Chapter 4) have banned doping and therefore aim to retain the separation between the natural and the artificial.

Within the study of sport, the use of the natural/artificial binary has meant that, at times, examinations of sport and technology have revolved around the question of whether the natural creates the artificial or the artificial creates the natural. In terms of sporting performance, this includes the question of whether a human performance inspires the creation of new technological devices or whether new technologies create the human performance. With technological determinism at one extreme end, it has been argued that technology develops separately from the social context where it is used, but that, once used, it then determines social practice (Roe Smith and Marx, 1994). At the other extreme end, it is theorised that technology and its resulting consequences are initiated entirely by social actors, a theory that falls under the vague category of the social shaping of technology, or SST (Bijker and Law, 1992; Mackenzie and Wajcman, 1999; Rosen, 1993; Varney, 2002). For example, Rosen (1993) argued that the specific design of the mountain bike resulted from the environment around where the bikes were being made. He described how one bike design, the clunker, became popular in Marin County, California, both because it was suited to the terrain and because the users had positive cultural associations with the Schwinn Excelsior bike frame that the clunker was made from. Similarly, Varney (2002) described how the creation of women's artistic gymnastics equipment was a result of the social position of women. She argues that each apparatus was designed to require less strength and more grace and flexibility than the previously existing men's apparatus. She theorised that this was a response to the predominant male/female binary that assumes females to be less physically capable. Further, Eichberg (1982) argued that the stopwatch developed as a result of behaviour. He describes how it came about because of a change in thinking about physical exercise, from purely exercise or 'exercitia' to that of a quantified competition in the form of 'sports' (p. 47). 
Eichberg (1982, p. 44) opens up the question of whether 'behaviour is derived from objects or from behaviour' by concluding that answering this question is unnecessary for understanding the relationship between technology and sport. Instead, he argues that the natural/artificial binary has never been clear.

The overall argument that the natural/artificial binary is overcome through a concept encompassing multiplicity has been raised by several authors. Deleuze and Guattari (2004) preferred the term 'assemblage' but referred to the same phenomenon. Haraway (2004) similarly adopted this idea through her work on the cyborg, while ANT theorists Latour (2005) and Law (1994) used the term 'network' and Mol (2002) 'multiple. For all these authors, the common thread is the argument that the make-up of the world makes it impossible to separate the natural from the artificial or the human from the non-human because they are intertwined in our everyday lives.

Similarly, writing on sport, Tangen (2004, p. 16) uses the word 'system' to describe the network that makes up sport. While most researchers who examine technology investigate specific improvements or implements, Tangen argues that facilities are an equally important part of the sporting network. He notes that the facility forms a significant role in determining how the sport will be played, and in allowing sport to be played:

The facility is not only a sufficient structure of sport. It is a necessary structure; a structure of embedded expectations. Without a facility there will be no sport. The sport and the facility are two sides of the same coin.

In acknowledging the equal importance of the structures of sport and the facilities, Tangen approaches the perspective adopted in ANT in arguing that the social and the technological should be treated symmetrically.

Also within the study of sport, Butryn and Masucci (2009), following Ihde's (2010) perspective, move towards understanding athletes as actor-networks through their use of the concept of a cyborg. They identify three forms the relationship between human athletes and technologies can take: first, technology as mediator; second, technology as embodied or an extension of the body (which most closely resembles Haraway's concept of the cyborg); and third, technology as providing an alternative or other-world experience (Butryn and Masucci, 2009). The distinction between humans and technologies remains, and the focus is on understanding the relationships that humans have with technologies (Verbeek, 2005). By contrast, this book, in line with 
the aims of ANT, is interested in tracing the workings of sport as an assemblage of human and non-human (technological) actants and in unravelling the networks that produce sport. What the two approaches share is an acknowledgement of the central position of non-humans in the production of sport; however, ANT argues against any concept of the purely human existing as distinct from the non-human. Instead, ANT argues that social relations are always socio-technical and that humans and non-humans should be treated as equally able to produce action (Latour, 2005).

\section{Technology as society made durable}

Latour argues that technology 'is society made durable' (Latour, 1991, p. 103). This obscure statement refers to his argument that nothing in the world is able to stabilise without the presence of non-humans. He argues that no purely 'social' world can ever exist, but the world works through the heterogeneous network of humans and non-humans, and that it is the way that the two are assembled together that produces stability.

In order to illustrate his argument that the world is always socio-technical but stabilises through the combining of human and technological entities, Latour (1992) uses the very simple example of a door. He argues that one way of understanding the equal importance of the social and the technical in society is to imagine the work that must be done by a human if the non-human were to be removed. In the case of the door, he describes how a hole would have to be made in a wall and then bricked back up in order to fulfil the same purpose as a door. If the door were removed and the hole left open, outdoor weather such as rain and wind would be able to enter indoors, making it pointless to be inside at all. With the door present, it is through the combined efforts of a human and non-human that one is able to walk through. The human has been involved in the creation of the door, in walking through and pushing or pulling the door open and closed. But this is only possible through the physical properties of the door being combined in a particular way. The door is hinged, allowing it to move freely, and made of a robust, hard material that means it will prevent weather such as wind and rain getting through.

With the door in place, the method of entering and exiting the building without allowing rain or wind inside becomes stabilised. Humans and the physical components of the door are disciplined to work together to allow entering and exiting to occur, and this behaviour is now stabilised as the dominant way in which actors enter buildings. 
In sport, we can similarly see the same stabilisation of behaviour through technology as sports become stabilised networks that utilise particular pieces of technology. Many sports are now stabilised as including particular balls, bats, boats and many other technologies as part of their normalised form of operation. For example, van Hilvoorde, Vos and de Wert (2007) note the stabilisation of the high jump as including a bar, mats and the technique of the 'Fosbury Flop'. They discuss how it has been assumed that in the sport of high-jumping the now common technique of the 'Fosbury Flop' developed as a result of the creation of foam mats for high-jumpers to land in. However, Dick Fosbury actually created the 'Flop' prior to the introduction of mats. Rather, the mats allowed the 'Flop' to become the norm for high-jumpers after Fosbury first performed it with great success. Therefore it was the assemblage of the mats together with Fosbury's success that produced the current norm of the Fosbury Flop being the normal way to high-jump. The behaviour of the high-jumpers, in utilising the Fosbury Flop technique, has become stabilised as a result of the high-jump network, including landing mats and the exact technology used to hold the bar to the side supports. With regard to the latter, Dick Fosbury described how he experimented with working out which parts of his body were causing the bar to fall and created the 'Flop' as a way to avoid those body parts knocking against the bar (van Hilvoorde, Vos and de Wert, 2007). Fosbury's experimentation suggests that the particular technology of the bar itself, and how it was attached to the stand and falls off, were also significant in determining what would cause it to fall. If the bar had been attached through different means, it is possible that the Fosbury Flop would not have been as effective, and a different method of jumping might have stabilised as the norm.

The example above demonstrates how the heterogeneous or multiple aspects of a particular technique or technology can become concealed from view once it stabilises. The way that multiplicities become understood as singular and stabilised has been of particular interest to the ANT researcher Annemarie Mol, whose work on atherosclerosis demonstrated the way that the disease existed in multiple forms and incorporated multiple meanings despite being assumed to be singular (Mol, 2002). In sport, a similar example can be found through the example of doping, where the very different acts of finding banned substances in a person's blood, taking a pill or injecting oneself are singularly considered to be doping, even though these practices are very different and are undertaken by different groups in different contexts.

Once a network has stabilised, Latour (1991) uses the term 'black boxed' and Law (1992) 'punctualised' to refer to the way that the network becomes 
understood as referring to that particular concept and therefore the network that created it becomes lost from view. The best example of 'black boxing' (Latour, 1991) in sport occurs through rules and regulations. All sports now have countless rules and regulations in place that exist in written form as inscriptions. These have been produced in order to ensure that the sport runs effectively and that a winner can be determined fairly and appropriately, but they were not created arbitrarily. Many rules have come into effect because of occurrences of inappropriate behaviour or similar circumstances that required sanctions against particular behaviour to be included in the rules to prevent it happening again. However, the actual behaviour behind the decision to change the rules is now concealed from view. The sport stabilises, or becomes black-boxed, with particular rules in place that remain an unquestionable part of the sport. For example, in sprinting, the International Association of Athletics Federations (IAAF) introduced the rule that the winning athlete is the one whose chest moves over the finish line first because of the problem of determining which athlete was the winner (Inizan, 1994). I consider a more detailed case in swimming, where particular regulations were introduced to counter problematic behaviour, in Chapter 2.

\section{Technology as actant}

The above discussion of the high jump highlights the way that technologies can 'act' to alter or influence sport. One of the most extensive and controversial debates within both ANT and wider literature is about how it is that non-humans such as technologies, incapable of conscious decision-making, are able to act (Sayes, 2014). Arguably ANT's most extreme critics, Collins and Yearley (1992), claim that ANT overstates the importance of non-humans in the social world and suggest that the study of technologies is better left to the physical sciences than the social sciences. Given this controversy, it is to the question of how technologies can act that I now turn my attention.

In sport, there can be no doubt that technologies have had a significant impact. At the simplest level, we know that improvements in technology can contribute to enhanced athletic performances. For example, in attempting to determine the effects that technology can have on sport, Haake (2009) used statistical analysis specifically to examine the effect of new technology on the sports of sprinting, pole vault, javelin and cycling. He historically tracked the performances of athletes together with changes in technology. He found that in pole vault and cycling there were clear historical 'jumps' in performance as a result 
of improved pole or bike technology. Conversely, in javelin, he found that in 1984 the rules for the technology permitted in the javelin itself were restricted, and as a result performance levels actually declined in the years following. His 2009 study is interesting as it acknowledged that rules can have the same power as new technologies. In making this acknowledgement, he called attention to the heterogeneous nature of sport and the way that sporting performances are affected by a variety of different facets. He argued that both the technology and the rules acted to influence performance.

Haake (2009) was particularly interested in the way that technologies had a causal effect on sporting performance. In the sports he chose to examine he found a very direct relationship. This kind of work is important in understanding technologies, and a statistical methodology allows the numerical identification of direct effects in sports where measurements are key. The ANT methodology allows the investigation of a wider range of complexities, including cases where it can be difficult to identify numerical effects. Indeed, Latour notes that in terms of causality, there are:

many physical shades between full causality and sheer inexistence. In addition to 'determining' and serving as a 'backdrop for human action', things might authorise, allow, afford, encourage, permit, suggest, influence, block, render possible, forbid and so on. (2005, p. 72)

In this passage Latour highlights the many different roles that technology can hold beyond direct causality as identified by studies such as Haake's (2009).

In order to determine the role that a particular technology has played, Latour (1999b) argues that in many cases we become aware that a technology has acted through the existence of controversies. If technologies were simply instruments, as he accuses Heidegger of suggesting, then there would be little controversy about them. Instead, the use of technologies is constantly debated. As Matthewman (2011) chronicles, technologies as diverse as bridges, baby bottles and computers have all caused immense controversy in terms of their design, use and placement. They still hold value through the functions they can perform, but functional value is only one aspect of their existence.

There have been a range of controversies with regard to the use of technology in sport. While this book examines some of them in detail, such as doping and the use of the polyurethane swimsuit, there have been other landmark cases, including the case of Oscar Pistorius. Pistorius became caught in a controversy because his artificial legs were accused of acting too strongly and thus providing him with an advantage. To Pistorius himself, his artificial legs were 
his only means of locomotion and, given the choice, he would have preferred to be able to use flesh and bone. But to others, his artificial legs were seen as providing him with an advantage over other athletes. Pistorius's case highlights how, in comparison with Haake's (2009) study above, it can be extremely difficult to determine the effects that a new technology may have on sport. It took years for a verdict to be reached, which determined that Pistorius's artificial legs did not provide him with any unfair advantage.

One of the arguments for why technologies can create controversies is their transformative potential. The addition of a new technology, or object, to any environment can create extensive new possibilities, particularly when assembled with a human (Harvey and Knox, 2014). When a hammer is combined with a human, the human becomes capable of action that could not previously be performed. The human is transformed into a new assemblage, or a new network is created (Latour and Venn, 2002).

In the sporting context, it is precisely this notion that makes sport so appealing. The ability for an athlete to perform feats that might normally be seen as super-human can be very attractive to both observers and practitioners. It is the athlete combined with numerous different types of technology that allows them to transform from a 'normal' human into one capable of performing impressive physical achievements. As described earlier, a human in possession of a pole vault is suddenly transformed into a person capable of jumping several metres up into the air. A swimmer wearing a specially designed swimsuit swimming in a carefully designed pool having been trained by a scientific process is transformed into a person capable of moving through the water at astonishing speeds. It is these transformations that make sport enjoyable to watch.

The difficulty for the researcher is in determining the exact way that the technology has acted to create such a transformation. Haraway, in an interview with Penley and Ross (1990), frames this as a problem of language, where scholarship has developed a vocabulary for describing and explaining the actions of humans, who can use language to describe their actions, but no such vocabulary is available to non-humans, who are unable to speak.

As discussed in the introduction, much of this book is designed to follow sport and technologies that have been particularly controversial in the last decade. Latour (2005) uses a particular term to designate those technologies that behave in a controversial or unexpected manner: mediators. He defines mediators as objects whose outcome cannot by assured by their input. By contrast, he describes the opposite as 'intermediaries': non-controversial things which behave in a particular, predictable way (Bencherki, 2012; Latour, 2005). For example, in the context 
of sport, a stopwatch which accurately recorded the time an athlete takes to do a particular thing would be a common intermediary. The stopwatch would obediently begin recording when a certain button was pressed, and would stop when the button was pressed again. However, many things do not behave so obediently, including some stopwatches which may refuse to display any numbers at all, or refuse to acknowledge that the stop button has been pressed. Stopwatches that behave like this would be described by Latour (2005) as mediators: unpredictable objects where the outcome is not assured. These distinctions are significant, as mediators demonstrate how it is that non-humans can act to prevent, change or inhibit action, while intermediaries act to facilitate action. Latour argues that in all contexts humans work together with non-humans in order to function, and that therefore both the human and non-human can cause action. In the use of the stopwatch, a human pressing the wrong button and the plastic button not working have the same effect, of not causing the correct number to be displayed. Agency is shared between the human and the stopwatch in creating this outcome through the assemblage of the two (Bencherki, 2012; Latour, 2005).

Such a view reverses the standard sociological conception of agency. For ANT theorists, agency is produced through a heterogeneous network rather than individually. In the stopwatch example above, agency is produced through the combination of plastic and electronics that is the stopwatch working together with a human and their knowledge of which button should be pressed. Latour emphasises that it is the size, shape and scope of the network that determines what is produced. Different kinds of actor-networks produce different kinds of effects (Edwards and Nicoll, 2004).

One particular effect that Latour (1992) argued technologies can have is a moralising effect. He argues that technologies are increasingly utilised in order to discipline humans into behaving in a moral manner. This argument relates strongly to Foucault's work, which acknowledged the way that physical technologies and architecture, such as cameras or prison structures, are part of the process of disciplining individual humans to behave in particular ways (Foucault, 1977; Kerr, 2014). The example that Latour uses to demonstrate his argument is the network of the car. He describes how the law decrees that, when humans are in a car, they should wear a seatbelt in order to ensure their own safety and points out that modern cars have disciplining mechanisms to ensure drivers and passengers do so. He notes how cars commonly make a beeping sound, or flash a light, if a seatbelt is not worn. The beeping sound or the flashing light then acts as a device to discipline the driver to behave according to the law and wear a seatbelt. 
In sport there are countless examples of sporting bodies and regulations using technologies to ensure that athletes behave according to the rules. For example, at the beginning of skiing and snowboarding races, the racer must wait for a barrier to open before they can begin the race, to discipline athletes to begin at the correct time. Similarly, in sprinting, the starting blocks contain sensors to ensure that the athletes do not begin racing (in a 'false' start) before the official start of the race. In both these cases, the technologies act to discipline athletes into behaving according to the rules.

Technologies can also act to discipline spectators. All major sporting events include a range of infrastructure that disciplines those attending the games. For example, the lack of parking provided at the Olympic stadium disciplines visitors into travelling by train to arrive at the venue. Similarly, stadiums for many major sports are constructed to ensure that different groups of people are restricted to different areas. For example, in his examination of facilities, Tangen (2004) describes how a Premier League football stadium is demarcated to allow only certain individuals into particular areas. Players, managers and coaches are permitted in some areas, fans with tickets in another, and fans without tickets are not allowed in at all. In this example, it is clear that 'tickets' and other credentials transform the individuals into assemblages who can enter particular spaces. It is not the individual who is permitted into the area, but rather a credential that allows access. The credential acts as an inscription, containing the information about who the individual is that transforms them into someone who can enter that area or not, and works as a disciplinary mechanism to ensure that only particular people can enter particular areas.

\section{Conclusion}

This chapter has introduced the notion of technology and sport as consisting of actor-networks made up of heterogeneous components. This book does not view technology as having any particular, clearly defined roles in sport; instead I adopt the position that each technology exists as its own unique actor-network within a broader actor-network that constitutes sporting practice. There are no particular qualities held by any technology that makes it definable as a technology; rather, it is the network of the sport, and what is brought into the network as part of the sport and recognised by the network as a technology, that makes a technology definable as such. This is in line with the ANT view that researchers should be learning from the actors about their world (Latour, 1991). As Latour (2005) 
describes, any societal group spends a great deal of time defending its status as a particular group and policing the boundaries of the group. Sport is no exception. Those involved in sport are greatly concerned with what constitutes sport, and certain objects are accepted as technologies which are embraced within sport while others are banned. One of the goals of this book is to track the trajectories of these technologies, some of which allow new technologies to be easily integrated into sport and some of which do not.

The following chapter takes up the notion that technologies are not always easily enrolled in sport. Through specifically examining technological enhancements, the book now moves to consider how functionality is an insufficient reason for the adoption of new enhancements in sport. 